\title{
Corpo e Sociedade: da dietética à liberdade criadora
}

\author{
Fernando do Nascimento Gonçalves*
}

\begin{abstract}
Resumo
O presente trabalho trata da construção social da noção de "corpo" na cultura contemporânea, tendo como pano de fundo a discussão sobre os processos de produção de subjetividade. Seu objetivo é articular a questão do corpo - veículo da expressão de determinados valores sociais e culturais - com a possibilidade da desconstrução de seus códigos, a partir de experiências da arte contemporânea e, especificamente, da arte da performance.

Palavras-chave: arte, performance, corpo e subjetividade.
\end{abstract}

\section{Nota introdutória}

O presente artigo nasce de uma série de questionamentos presentes em minha pesquisa de doutoramento sobre a construção social da noção de "corpo" na cultura contemporânea. O estudo tem como pano de fundo a discussão sobre os processos de produção de subjetividade e procura articular a questão do corpo - veículo da expressão de determinados valores sociais - com a possibilidade da desconstrução dos códigos que ele encarna e pressupõe a partir de experiências da arte contemporânea e, especificamente, da arte da performance.

Neste sentido, interessará aqui discutir as formas de poder que as construções sociais de significados do corpo parecem constituir no campo da subjetividade, uma vez que gostos, comportamentos e escolhas, embora vividos a partir do indivíduo, parecem corresponder a determinados princípios e regimes de poder que têm seu registro no social.

* Mestre em Comunicação pela UFRJ, professor do Curso de Comunicação Social da Universidade Estadual do Rio de Janeiro (UERJ).

Comun. Inf., v. 3, n. 2, p. 218-232, jul./dez. 2000 
Assim como as relações que presidem as trocas e o consumo de bens materiais não são naturais, o corpo e os processos de identidade são produzidos socialmente, como conceito e como política. A noção de "corpo" seria, portanto, uma construção, uma "pele cultural" que cria territorializações e topofica os modos de ocupação do espaço.

Ora, os sistemas de troca e consumo de bens, as próprias formas de uso do corpo, as formas de relação consigo mesmo são "práticas de si" que expressam discursos da sociedade sobre si mesma e também uma forma de os homens falarem sobre si para si mesmos e para os outros homens. Mais do que isso: poderiam ser entendidas como forma de os homens viverem em si as marcas de seu tempo e dos regimes de força a elas correspondentes e que produzem códigos que muitas vezes se cristalizam. Ao se cristalizarem, esses códigos se naturalizam e reificam um certo estado de coisas, formulando, por vezes, estilos de vida, sensibilidades e visões de mundo homogeneizantes, nos quais se imiscuem formas de controle e dominação.

Será preciso, então, investigar e discutir as condições de possibilidade de instauração de práticas de si que possam desnaturalizar certos códigos sociais que implicam coerções e permitam o surgimento de estilos passíveis de instaurar a diferença. Nosso objeto será, portanto, práticas de si que favoreçam um necessário esquecimento do que está dado para dar lugar ao possível, ao singular.

Se o corpo é signo, pretende-se aqui fazer uma aposta nas artes corporais, em especial na chamada arte-performance, por sua possibilidade de constituir um vetor de potencialização de experiências de desregramento de códigos e de singularização da subjetividade.

\title{
2 Corpo, cultura e processos de significação
}

\author{
"É próprio da natureza da sociedade exprimir-se \\ simbolicamente em seus costumes e em suas instituições; \\ contrariamente, as condutas individuais jamais \\ são simbólicas por elas mesmas: são os elementos \\ a partir dos quais um sistema simbólico, \\ que só pode ser coletivo, se constrói"
}

Levi-Strauss

Jovens passeiam pelas ruas enquanto ouvem música em um walkman. Antropólogos apresentam vídeos a tribos indígenas, em so-

Comun. Inf., v. 3, n. 2, p. 218-232, jul./dez. 2000 
ciedades ditas primitivas, e percebem que estes os consideram objetos divertidos, mas como um outro qualquer.

Ao apresentar essas cenas, Guattari (1999:33) propõe pensar como as diferentes formas de comportamento em sociedade podem ser cada vez menos compreendidas do ponto de vista de uma simples escolha individual ou mesmo grupal.

No primeiro caso, ao produzir um walkman, a indústria não está produzindo apenas algo que transmita música ou organize sons. É toda uma relação com o universo e com os objetos musicais que está sendo criada. Desconstruindo as formas tradicionais de fruição musical, quando esta era "o" espetáculo, "ouvir música no walkman enquanto se caminha" representa uma nova forma de percepção que se inventa: uma música que vem "de dentro" e não do exterior e que pode ser ouvida enquanto se faz simultaneamente outra coisa.

No segundo caso, percebe-se o quanto o tipo de comportamento que consiste em ficar inteiramente focalizado no aparelho de televisão, numa relação de comunicação direta, só existe em nossa sociedade. De fato, é ela que o produz.

E o que dizer do desejo de posse e das formas de usar um celular, um carro ou uma casa? Dos nossos hábitos alimentares e de vestuário? Ou das idealizações do corpo perfeito, seja vestido, nu ou para ser visto, desejado, vendido, sentido ou mesmo escondido? Para Guattari, a produção da fala, das imagens, da sensibilidade, a produção do desejo não se cola absolutamente à representação do indivíduo. Antes, essa produção é "subjacente a uma multiplicidade de agenciamentos sociais, a mutações de valor" (Guattari, 1999: 32).

É essa multiplicidade que consubstancia a ordenação de significados de pessoas e coisas e as motivações para seu consumo, e que as inscreve num verdadeiro sistema de significação, que é a cultura. Nessa mesma direção afirma Sahlins, ao fazer uma crítica da noção utilitária da cultura e do comportamento social: "Os homens não 'sobrevivem' simplesmente. Eles sobrevivem de uma maneira específica" e produzem objetos para "sujeitos sociais específicos, no processo de reprodução de sujeitos por objetos sociais" (Sahlins, 1979: 187-188). E completa afirmando que a produção seria algo maior e diferente de uma prática lógica de eficiência material. Trata-se de uma intenção cultural, que somente pode ser apreciada a partir de um outro ponto de vista:

Comun. Inf., v. 3, n. 2, p. 218-232, jul./dez. 2000 
"é por sua correlação com um sistema simbólico que as calças são produzidas para homens e as saias para as mulheres, e não pela natureza do objeto em si nem por sua capacidade de satisfazer uma necessidade material (...) Nenhum objeto, nenhuma coisa é ou tem movimento na sociedade humana, exceto pela significação que os homens lhe atribuem" (Sahlins, 1979: 189).

Ora, o corpo constitui também um sistema simbólico e uma de nossas mais antigas e complexas instituições sociais. E talvez uma das menos visíveis enquanto tal. Graças a ele definimos nossa identidade de humanos, nos diferenciamos das coisas e de outros humanos e hierarquizamos nossas relações com eles. No entanto, com o avanço da tecnologia, da medicina, dos transportes e das comunicações, verificamos que a base que lhe dava sustentação entra em crise: sua presença. Ironicamente, talvez tenha sido preciso o advento do ciberespaço e da realidade virtual para pensarmos no corpo exatamente por sua ausência.

No momento em que podemos nos comunicar a distância, virtualmente, em que implantamos próteses, em que se tornam possíveis clonagens e que a pergunta que podemos fazer deixa de ser "que corpo sou" e passa a ser "que corpo quero ter", é todo um conjunto de possibilidades que se abre para um deslocamento de nós mesmos e para a recolocação de questões como a da identidade, a do próprio estatuto do humano e da vida em sociedade. Foi, em parte, graças à introdução e à aceleração da técnica em nossas relações com o corpo que se tornou possível percebê-lo também, e finalmente, como passível de estabelecer códigos.

Para Tucherman, a crise do corpo é "caudatária da crise dos fundamentos de nossa cultura e se articula com a crise do sujeito" (1999:23), que tem, por sua vez, como condição a clássica distinção entre o objeto que era (sujeito) e o mundo do qual aprendemos sempre a nos destacar. Logos e physis: a partir desta dualidade é que o corpo sofreu um longo processo de constituição e invenção, rupturas e metamorfoses, o que nos permitiria dizer que o corpo tem uma realidade lógica, ou seja, de "logos", o que contraria todas as evidências, segundo as quais somos naturalmente "physis".

Tomamos aqui a noção de corpo como construção, uma vez que o que temos basicamente é um conjunto de carne, músculos, ossos e sangue, mas a totalidade corpo (vestido, dócil, másculo, feminino, ci-

Comun. Inf., v. 3, n. 2, p. 218-232, jul./dez. 2000 
dadão, estrangeiro, estetizado, saudável, doente, monstruoso, cósmico etc) nasce de mediações, de formas discursivas que geram alteridades como teias de significação que permitem processos de classificação do idêntico para gerar exclusões.

Na verdade, nossa experiência do corpo sempre se deu por jogos, pois, como anota Tucherman (1999: 106), o corpo é talvez o mais político dos conceitos ocidentais - suporte de um conjunto de atributos que estruturam nossa lógica. Na pólis grega, por exemplo, o corpo das mulheres e dos escravos eram alteridades contidas num jogo de identidade e exclusão, eram corpos "do outro", submetidos a regras sociais particulares.

O corpo é, portanto, histórico e nasce ligado à cultura. Sua imagem é a de um artifício cultural que deve estar preparado para o espaço social e que sustenta a produção de processos de identificação e controle pelas marcas com as quais expõem os sujeitos em sua relação consigo e com o mundo. Seus limites e suspensões na atualidade são a própria fronteira da experiência do humano que pode sempre se tornar outra coisa.

Dessa forma, podemos considerar as diferentes concepções do corpo ao longo da história e, principalmente, na atualidade, como expressões de códigos sociais capazes de reger desejos e condutas. A este propósito, é interessante observar as anotações de Paulo Vaz sobre a experiência subjetiva de cuidado do corpo na sociedade. Para Vaz, a análise desse cuidado é estratégica e "viabiliza historicizar a experiência ao situar o corpo como nó de múltiplos investimentos e inquietações sociais" (Vaz, 1999: 159).

É assim, por exemplo, que, segundo Foucault, os gregos estabelecem com o corpo uma relação com a força e com a vida, e no cristianismo o corpo resume uma atitude de culpa e recusa da vida. Seguindo esse raciocínio, Vaz chama atenção para o fato de que desde o início do capitalismo se buscava criar corpos dóceis e disciplinados para a produção. Mais tarde, os corpos começariam a entrar para o mercado, como capacidade de consumir e, ao mesmo tempo, como objeto de consumo.

Na atualidade, observa Vaz que esse corpo que consome é cada vez menos investido como força, e sim, como máquina de prazer e dor, que tem como preocupação a aparência e o não-adoecer, uma vez que se tenta a todo custo negar sua finitude. "O corpo contemporâneo quer comprar a possibilidade de se manter vivo e belo e não é à

Comun. Inf., v. 3, n. 2, p. 218-232, jul./dez. 2000 
toa que a indústria que mais cresceu nos últimos 30 anos é a farmacêutica, vendendo juventude, bem-estar e beleza. O corpo consome principalmente a si mesmo" (Vaz, 1999: 163).

Daí podermos falar no corpo contemporâneo como um corpo da dietética, que mede suas ações pela possibilidade de correr riscos. Trata-se, segundo Vaz, da passagem da sociedade de disciplina para a de controle, anunciada por Deleuze. Na primeira, o perigo era objetivado por um fator externo, como delinqüência, loucura ou perversão sexual e, para tanto, utilizavam-se "da correção pela reclusão, medidas de higiene e moralização das classes perigosas” (Vaz, 1999: 171). Já na sociedade de controle, a objetivação do perigo permite a subjetivação como informação sobre riscos de vinculação a práticas. Ou seja, para se evitar o câncer torna-se necessária uma mudança de determinados hábitos, assim como para se evitar Aids será preciso utilizar preservativos na relação sexual e usar agulhas e seringas descartáveis em transfusões de sangue. O controle não é mais exterior, ele agora vem de dentro.

O corpo diet seria, sobretudo, o corpo que vive uma moratória ilimitada: uma dívida que não se tem a ilusão de pagar, mas cuja cobrança apenas se pensa em adiar (Vaz, 1999: 174). E essa moratória constrói um modelo neoliberal de subjetividade, em que o bem-estar, articulado ao consumo, propõe como finalidade da vida consumir sem se consumir. Mas esse eterno adiamento é também um modo de ajustar e padronizar comportamentos, e, portanto, de controle subjetivo. Neste ponto perguntamos: então, o que nos é dado desejar?

\section{Subjetivação e desnaturalização de códigos}

É interessante observar como na história recente do Ocidente o discurso sobre as formas de vida, sobre o outro e sobre a diferença, através de diferentes instâncias (artísticas, midiáticas, literárias, científicas), vem muitas vezes sendo produzido dentro de perspectivas que interditam diferentes visões de mundo, sistemas de valores e percepções da realidade. Por outro lado, sempre existiram possibilidades de resistência a essas perspectivas, surgidas, não raro, a partir das próprias instâncias nas quais se articula esse discurso.

Para fortalecer esse argumento, recordamos que Foucault nos fala do surgimento de uma "nova era de curiosidade", em que se poderia explorar as potencialidades das novas técnicas na direção de uma trans-

Comun. Inf., v. 3, n. 2, p. 218-232, jul./dez. 2000 
formação. Foucault procura, assim, afastar-se do discurso segundo o qual tudo vai mal e de que vivemos num vazio sem futuro: "Ao contrário, acredito que há uma pletora. Não estamos sofrendo de um vazio, mas de meios inadequados para pensar sobre tudo o que está acontecendo" (Foucault apud Caiafa, 2000: 61).

Trata-se, portanto, de investigar e criar novas formas de produzir heterogeneidade e romper com as modelizações dominantes. Mas as operações capazes de produzir heterogeneidade e modos de vida singulares dependem de certas inflexões da subjetividade. Trata-se daquilo que Foucault chamou de processos de subjetivação, ou seja, da constituição de nossas próprias formas de existência em sociedade, da possibilidade de imaginar e construir o que poderíamos ser, tentando livrar-nos da "individualização e totalização das estruturas de poder". E, como pontua Deleuze sobre Foucault, em entrevista a Didier Eribon (Deleuze, 1992:123), essa noção de subjetivação, que possibilita a constituição de novas formas de existência, permitiria perceber a criação de modos de vida segundo regras facultativas, formas de cuidado de si, de uma "estética da existência", de existir não como sujeito, mas como obra de arte.

Tal disposição para um trabalho com a subjetividade pode ser potencializada quando associada à noção de produção de subjetividade de Guattari, quando ele afirma que os processos de produção de sentido da existência não se centram nem em uma entidade individuada nem em agentes grupais. É um mecanismo que põe em conexão diferentes instâncias (intrapsíquicas, sistemas econômicos, tecnológicos, midiáticos, de percepção, afeto, imagens, sistemas corporais, biológicos) (Guattari, 1999: 31).

A subjetividade seria então entendida como essencialmente social, mas assumida e vivida por sujeitos em suas vidas particulares, onde é sempre possível seu remodelamento. Na realidade, segundo esse raciocínio, consumimos sistemas de representação, de sensibilidade, que vão produzir determinados sentidos que se cruzam com outros tantos:

Daí a noção de "produção de subjetividade capitalística", que corresponde exatamente aos sistemas de modelização da existência, que se dão cada vez mais apoiados em uma serialização, própria das sociedades capitalistas. Esse tipo de subjetividade estaria concorrendo para um grande empobrecimento do que Guattari chamou de "qualidades singulares", que poderiam criar arranjos diferenciados no pro-

Comun. Inf., v. 3, n. 2, p. 218-232, jul./dez. 2000 
cesso de produção de sentido por se darem no nível do desejo e constituírem o locus da contestação das modelizações dominantes. Tratase, pois, de produzir resistência e, ao mesmo tempo, "secretar novos campos de referência”, no que a arte poderá ser uma interessante aliada.

É nesse sentido que Caiafa (2000:66) aposta que a arte possibilitaria "experimentações subjetivas", na medida em que seriam as "máquinas estéticas, que, em seu trabalho de experimentação com a expressão, podem abrir brechas nas subjetividades padronizadas", singularizando-as. A singularização da subjetividade, marcada por um "devir diferencial", teria o poder de frustrar e, ao mesmo tempo, subverter os mecanismos de modelização, afirmando novos valores e modos de vida mediante um processo de reapropriação da própria subjetividade - processo de subjetivação - e seus vetores, por meio de usos singulares da mídia, das relações de trabalho, das relações pessoais, políticas, da vivência do cotidiano etc.

De fato, essas experimentações poderiam desempenhar o que Caiafa chamou de uma "função poética", mediante a qual diversos elementos existenciais dispersos poderiam ser captados e catalisados de forma transformadora (Caiafa, 2000:67). É nesse contexto que se insere a discussão sobre o corpo e a arte da performance.

\section{Práticas de liberdade: o corpo na arte da performance}

Segundo Philip Auslander (1997:169), a performance como movimento conceitual de arte surgiu entre os anos 60 e 70, como uma reação à mercantilização dos objetos de arte e uma crítica à "cultura midiatizada". Teve como precursores os movimentos experimentais da body art e do happening. Os termos body art e happening agrupavam diversas tendências internas, mas tinham como denominador comum a proposta de, como afirma Glusberg, "desfetichizar o corpo humano - eliminando toda exaltação à beleza a que ele foi elevado durante séculos pela literatura, pintura e escultura - para trazê-lo à sua verdadeira função: a de instrumento do homem, do qual, por sua vez, depende o homem" (1987:43).

Nos anos 70, a body art se diluiria dentro de um gênero mais amplo - a performance. Mesmo expandindo-se pelos Estados Unidos, Europa e Japão, a body art dá lugar

Comun. Inf., v. 3, n. 2, p. 218-232, jul./dez. 2000 
"a que outros criadores interessados em pesquisar novos modos de comunicação e significação convergissem para uma prática que, apesar de utilizar o corpo como matéria-prima, não se reduz somente à exploração de suas capacidades, incorporando também outros aspectos tanto individuais quanto sociais, vinculados com o princípio básico de transformar o artista na sua própria obra, ou melhor ainda, em sujeito e objeto de sua arte" (Glusberg, 1987:43).

Glusberg chama a atenção para o fato de que o termo performance apresenta duas conotações: a de uma presença física e a de um espetáculo. Mas o caráter e a função desses elementos já não serão os mesmos das artes tradicionais como o teatro, a dança - de onde basicamente deriva a performance -, nem da pintura e da música. Antes, tratam das relações entre corpo e espaço, questionando-as e buscando renovar as próprias artes tradicionais.

Como já vimos anteriormente, o corpo é um signo. As atividades corporais estão determinadas por convenções que constituem verdadeiros "programas gestuais" a que nos sujeitamos, conforme os tempos e as condições da cultura em que vivemos. Nesse sentido, a performance busca desenvolver programas criativos, individuais e coletivos e o que nela interessa é o processo de trabalho, sua seqüência, seus fatores constitutivos e sua relação com o produto artístico. A partir disso, é possível verificar que a cultura nos leva a tomar por naturais seqüências de ações e comportamentos a que estamos habituados. $\mathrm{O}$ estudo das relações entre corpo e cultura permite uma decodificação e um questionamento das condições de geração dessas ações e dos fatores que as determinam (Glusberg, 1987: 53). Portanto a arte da performance não se ocupa do corpo em si, e sim, de seu discurso.

Para ilustrar a argumentação, tomaremos como exemplo o trabalho da performer americana Laurie Anderson, sob a ótica dos questionamentos de Rogério Luz acerca das relações entre arte e técnica, segundo os quais "um novo meio expressivo exige do artista uma nova prática e a uma nova prática deve corresponder uma nova lin. guagem" (Luz, 1993: 191).

Será interessante analisar, a partir do trabalho de performance de Laurie Anderson, como os diversos meios expressivos podem se articular com a criação de novas práticas e novas linguagens na arte e,

Comun. Inf., v. 3, n. 2, p. 218-232, jul./dez. 2000 
conseqüentemente, de "dizer e pensar" o mundo contemporâneo. Para tanto, sem a intenção de fazer biografia ou então de definir-lhe um lugar de onde, como "sujeito", estaria falando, será interessante trazer alguns dados sobre Laurie Anderson, não apenas por seu trabalho ser pouco conhecido no Brasil, mas sobretudo para abordá-lo sob uma perspectiva de descentramento, exatamente para demonstrar que não é necessário nem desejável definir ou classificar seu trabalho.

Escultora desde a década de 60, em Nova York, Anderson vem desde essa época associando-se a músicos como Philip Glass na downtown scene do Soho e engajando-se em vários "trabalhos-arte de performance" - com instrumentos musicais criados por ela própria - em espaços de arte "alternativos" dos Estados Unidos e Europa, sobretudo na década de 70. Será interessante observar que seu processo criativo tornou-se possível a partir de alguns deslocamentos realizados em sua trajetória. Da escultura associa-se à música sem, no entanto, se tornar música, mas aproveitando elementos musicais; mais tarde associa-se a elementos de teatro e, finalmente, aos tão conhecidos elementos da comunicação de massa, de audiovisuais e computação gráfica. Acionando e imbricando esses distintos elementos em seu trabalho, ficou conhecida como performer multimídia.

Ao ilustrar nossos argumentos com o trabalho de Anderson, reivindicamos duas outras conotações para a performance, além daquelas propostas por Glusberg: a da performance como arte de intervenção e de experimentação. Se a idéia de performance é derivada principalmente do teatro e da dança e é associada normalmente ao acting, ela ganha um significado mais preciso quando associada ao conceito de performatividade em Stimpson e Bahba (1996:189). Essa noção traz a idéia de que nossas vidas não expressam coisas naturais ou originais. Na verdade, para esses autores, nós construiríamos nossas vidas na medida da construção de nossas narrativas - performatizandoas como a papéis.

Daí temos a noção de performance como intervenção. Mas a noção de "intervenção" em si mesma parece ainda pouco clara, pouco definidora do caráter do qual parece estar imbuída a arte da performance. Mais do que um simples acting, a performance propõe novas experiências perceptivas e questiona certos aspectos do cotidiano, da cultura contemporânea.

É exatamente esse aspecto de desconstrução que vejo na arteperformance de Laurie Anderson. Estabelecendo uma imageria vi-

Comun. Inf., v. 3, n. 2, p. 218-232, jul./dez. 2000 
sual como parte integrante de seu trabalho, Anderson ficou muito conhecida por lançar mão de slides, computação gráfica e outros recursos para criar a animação de formações visuais que por vezes são narrativas e por outras, simples fenômenos visuais.

Suas criações, em princípio, são formas de pensar as possíveis relações entre cultura e técnica e as novas experimentações de linguagem na arte por meio de elementos de expressão da comunicação de massa e das novas tecnologias. Nesse caso, pensa-se sua aplicação para além de simples propostas comerciais, de forma que o uso que faz das imagens nãoé em si paródia - face à crítica feita à imageria dos meios de comunicação de massa, imagens tornadas clichês e que são comumentemente reproduzidas de forma a comunicarem significados comumentemente compreendidos - e, sim, apropriação desses mesmos recursos para fazer outra coisa.

Um outro aspecto que vale ser destacado é o tratamento que Anderson procura dar às formas narrativas e que parecem demonstrar sua preocupação não com o individual, mas com o coletivo: ela busca descolar a noção de sujeito/autor do processo narrativo, estabelecendo freqüentemente um discurso em terceira pessoa que remete à apresentação de outros discursos, de outras narrativas. No caso em questão, os usos e as apropriações da tecnologia e dos discursos midiáticos feitos pela artista (reproduções de conversas em secretárias eletrônicas, programas de TV e uso de aparelhos para distorcer a voz, por exemplo) parecem exatamente caracterizar um processo de criação capaz de tornar possível experimentar novas linguagens na música, no teatro e nas artes multimidiáticas.

Na verdade, ela parece hibridizar linguagens e mídias. O resultado não é nem música, nem teatro, nem audiovisual, é uma arte de intervenção, de potencialização de atos da língua, dos movimentos e das imagens, apoiadas em elementos do cotidiano e da cultura contemporânea.

No caso em questão, os usos e as apropriações da tecnologia e dos discursos midiáticos feitos por Laurie Anderson parecem exatamente caracterizar um processo de subjetivação capaz de tornar possíveis novas escrituras dessas experiências, de modos de vida não somente individuais, mas também, e sobretudo, coletivos. Seria o retorno à noção foucaultiana da estética da existência, em que seja possível uma "escrita de si", ou seja, formas de constituição da existência e de si próprio como "sujeito de ação racional pela apropriação, a unifi-

Comun. Inf., v. 3, n. 2, p. 218-232, jul./dez. 2000 
cação e a subjetivação de um 'já dito' fragmentário e escolhido" (Foucault, 1992:160). É nessas relações entre o homem e o "já dito"registro do social - e do homem consigo que se torna possível a produção de novos modos de vida.

Mas se fica clara a possibilidade da performance como intervenção, é com Guattari que ela vai ganhar o estatuto de experimentação. Afirma ele que a performance tem o mérito de levar ao extremo as percepções e os estados de alma banais, fazendo-nos passar do que estes teriam de mais padronizados a "formas radicalmente mutantes de subjetividade". Isto porque a performance carregaria "blocos de sensações compostos pelas práticas estéticas aquém do oral, do escritural, do gestual, do postural, do plástico... que têm como função desmanchar as significações coladas às percepções triviais e às opiniões impregnando os sentimentos comuns" (Guattari, 1992:114).

A performance potencializaria assim o instante, engajando-o num processo de "descentramento estético", em que os componentes de expressão e elementos retirados do cotidiano sofreriam extrações intensivas e passariam por uma desconstrução de suas estruturas e códigos para propiciar uma recomposição, uma recriação desses elementos. A performance seria, portanto, ao mesmo tempo um questionamento do natural e uma proposta artística, e a relação artecorpo, uma relação de enfrentamento.

O corpo, longe de ser a origem de nossos comportamentos, é uma matéria moldada pelos padrões sociais e culturais, um efeito possível da estrutura complexa da codificação social. Do ponto de vista da criatividade, a performance possibilita observar com clareza esse princípio, ao recuperar o corpo como veículo do fazer artístico e ao permitir repensar as relações que existem entre o conceito convencional de corpo e de suas práticas como algo natural.

A performance surge então como "uma emergência estética, como transgressão dentro de uma cultura em que o corpo, a partir das convenções vigentes, é alienado de si mesmo" (Glusberg, 1987: 75). A partir da experiência da arte da performance, as relações sociais e as formas culturais poderiam talvez dar forma a um corpo "mudo", permitindo novas oportunidades de experimentá-lo, o que significa violar antigas e acentuadas tradições estéticas e culturais. Como uma instância de estetização do corpo, a performance seria, nesse contexto, uma forma expressiva onde os códigos vigentes se enfrentariam com o novo

Comun. Inf., v. 3, n. 2, p. 218-232, jul./dez. 2000 
e o imprevisto, dando lugar a experimentações capazes de produzir novos agenciamentos entre corpo e sociedade.

\section{Notas finais}

Processos criativos como os da performer Laurie Anderson, sem querer fazer fixar o artista em si, parecem demonstrar a possibilidade de singularização de elementos da cultura e da linguagem. A aposta é que esses processos sejam vetores de produção de singularidades que tentem se esquivar da lógica de ordem e padronização subjetiva e dos mercados cultural e artístico, de suas instâncias de valoração e seus sistemas de circulação de bens simbólicos para experimentar, inventar, tornar-se criação e comunicabilidade.

O que o presente artigo propõe à reflexão, finalmente, são as possibilidades de pensar o corpo como objeto estético e de dar-lhe um uso político por meio da arte da performance. No caso, a experiência do corpo estaria localizada além do regime da "dietética" proposto pelas lógicas de mercado e do "corpo-controle", lógica capitalística de controle e consumo. E embora a arte não detenha o monopólio da criação, como explica Guattari", esta poderia "levar ao ponto extremo uma capacidade de invenção de coordenadas mutantes, de engendramento de qualidades de ser inéditas, jamais vistas, jamais pensadas" (Guattari, 1992:135), criando outra natureza de modalidade expressiva.

É dessa capacidade de invenção que essas novas experiências de si, do corpo e da comunicação, presentes na performance, poderiam estar imbuídas. Nessas experiências acredita-se estar ativado permanentemente o cruzamento de inúmeros vetores de produção de sentido, garantindo uma heterogeneidade, uma polifonia na qual os modos de vida teriam chances de resingularizar-se, de auto-escrever-se, produzindo diferença.

Se os modos de vida e as práticas sociais podem padronizar-se mediante sistemas de representação e de uma comunicação que elimina ao máximo a diferença, na performance a comunicação poderia talvez deixar de ser representação para ser apresentação de possíveis da realidade; e o corpo e a existência poderiam se virtualizar no sentido em que entende Deleuze, ou seja, opor-se a um atual pré-existente, para tornar-se outra coisa. Uma prática de liberdade e uma obra de arte, por exemplo.

Comun. Inf., v. 3, n. 2, p. 218-232, jul./dez. 2000 
Ora, se há um vazio subjetivo produzido pelo capitalismo, se nos encontramos hoje cada vez mais envoltos na solidão gerada pela desertificação dos espaços de troca, esse vazio só poderá ser suprimido por novas formas de cuidado, de subjetivação. Afinal, como afirma Guattari (1992:33), "a única finalidade aceitável das atividades humanas é a produção de uma subjetividade auto-enriquecendo de modo contínuo sua relação com o mundo".

\section{Abstract}

This paper considers the social construction of the notion of "body" in contemporary culture and has as background the discussion about the processes involved in the production of subjectivity. It aims to connect the notion of body - means of expression of certains cultural and social values - with the possibility of disconstruction of its codes, based on studies in contemporary art, specifically, the art of performance.

Keywords: arte, perfomance, body, subjectivity.

\section{Nota}

1. Aqui se refere Guattari, em Caosmose, à proposição de um novo paradigma estético, cuja aposta é a de que os processos de criação em distintas esferas do social têm aptidão para auto-afirmar-se como fontes existenciais, ou seja, como fontes de criação e constituição de diferentes modos de vida.

\section{Referências bibliográfias}

AMSPAUGH, Glenn. A look at Laurie Anderson and her Media Generated Appearence. Disponível em: <www.c3.lanl.gov/ jimmyd/interpretation/ termpaper.html>. Acesso em: 22/03/97.

AUSLANDER, Philip. Presence and resistance: postmodernism and Cultural Politics in Contemporary American Performance. $4^{\text {th }}$ ed. [S.1]: The University Michigan Press, 1997.

CAIAFA, J. Nosso Século XXI: notas sobre Arte, Técnica e Poderes. Rio de Janeiro: Relume-Dumará, 2000.

GUATTARI, Félix. Micropolítica: cartografias do desejo. 5. ed. Petrópolis: Vozes, 1999.

Caosmose. Rio de janeiro: Ed. 34, 1992.

GLUSBERG, Jorge. A arte da performance. São Paulo: Perspectiva, 1987.

LUZ, Rogério. Multimídia e linguagens contemporâneas. Rio de Janeiro: Notrya, 1993.

SAHLINS, Marshall. Cultura e Razão Prática. Rio de Janeiro: Zahar, 1979.

Comun. Inf., v. 3, n. 2, p. 218-232, jul./dez. 2000 
STIMPSON, Catharine; BHABHA, Homi. Global creativity and the Arts. Nova York: MacArthur Round Table background paper, 1996.

TUCHERMAN, Ieda. Breve historia do corpo e de seus monstros. Lisboa: Passagens, 1999.

VAZ, Paulo. Corpo e risco. In: VILLAÇA, Nízia (Org.). Que corpo é esse? Rio de Janeiro: Mauad, 1999.

Comun. Inf., v. 3, n. 2, p. 218-232, jul./dez. 2000 